\title{
On Inherent Incoherence of Gaunilo's Island
}

\author{
Edgar Danielyan \\ University of Buckingham \\ https://doi.org/10.1111/heyj.13056
}

\begin{abstract}
Various attempts have been made to save Gaunilo's 'ideal' island by proposing different criteria for its maximal greatness or perfection. This paper addresses a recent proposal that 'an ideal island is conceivable if it's defined as any island exhibiting an ideal ratio of great-making island properties' (Milo Crimi, 'Ideally sized islands: Reply to Danielyan, Garrett and Plantinga', Analysis 77 (2), 273-278) and shows that it fails because the idea of an island - indeed of anything that is finite, delineated and circumscribed as a necessary condition of its own conception - cannot accommodate maximal greatness or perfection; neither can a determined quantitative relation between finite relata constitute a criterion of maximal greatness or perfection.
\end{abstract}

Milo Crimi (2017) endeavours to save Gaunilo's island from the peril of incoherence by arguing that 'an ideal island is conceivable if it's defined as any island exhibiting an ideal ratio of great-making island properties' in response to Plantinga (1974: 90-91) and Danielyan (2015). I have earlier aimed to demonstrate that 'there is not exactly one ideal size for an island' by showing that the notion of an "“island of an ideal size" is meaningless without specifying some external contingent requirement of what constitutes ideal size, such contingent requirement being variable' (Danielyan, 2015).

Crimi contends that 'Perhaps then we can define an ideal island as any island exhibiting an ideal ratio of great-making island properties - that is, any island whose size to population to coconut count to sand color to air temperature to sea temperature to . . ratio is ideal' and adds that 'We needn't determine here just what island properties are great-making for islands' because 'Such a view accompanies a shift in our conception of greatness away from one measured by amounts of great-making properties. Instead, greatness might be measured by proximity to a given ideal ratio'. Alas, neither amounts nor ratios can give coherence to Gaunilo's island for the reasons discussed below regardless of the number of greatmaking island properties. If maximal greatness or perfection is 'every simple quality which is positive and absolute, or that expresses without any limits whatever it expresses' it follows that the fundamental criterion for $\mathrm{X}$ to be an island is for it to be limited by definition to the concept of an island which prevents an island from being maximally great or perfect (Leibniz, 1923). In other words the idea of an island precludes it from being maximally great or perfect.

Leaving aside the question of whether proximity to what is maximally great or perfect is a coherent notion I examine Crimi's central proposal, that of an ideal ratio of great-making properties. I submit 
that the move away from an ideal size of an island to an ideal ratio of great-making properties of an island fails to give coherence to the proposed concept of a maximally great or perfect island. Introducing an external criterion of ratio of 'great-making island properties' does not save Gaunilo's island, because proximity and ratios cannot be maximally great or perfect themselves (for a given proximity $\mathrm{P}$ a shorter and therefore more perfect, i.e. closer to the hypothesised ideal ratio, proximity P-1 can be proposed, and for a given ratio of $R\left(\mathrm{P}_{1}, \ldots, \mathrm{P}_{\mathrm{n}}\right)$ between a set of great-making properties $\mathrm{P}_{1}, \ldots, \mathrm{P}_{\mathrm{n}}$, a greater one can be proposed: $\left.\mathrm{P}_{1}, \ldots, \mathrm{P}_{\mathrm{n}+1}\right)$.

Perhaps degrees of greatness might be measured by proximity to a given ratio - but the question in hand is about maximal greatness or perfection, not just some contingent, finite and variable greatness in degree, given the context of St Anselm's discourse.

Maximal greatness or perfection therefore, in order to be maximal or perfect, cannot include by definition any finitude, limitation or constraint, and therefore cannot be nearer or further away from a ratio, since a ratio is by definition nothing but a determined quantitative relation between two or more finite relata that are necessarily not maximally great or perfect and Crimi accepts that 'these greatmaking properties are non-maximal'. And if it is determined and quantitative then it has an inherent limit to its greatness or perfection and cannot be maximally great or perfect since omnis determinatio est limitatio, to paraphrase Spinoza. Crimi does not demonstrate that all purported great-making properties of an island that are to constitute the proposed ideal ratio are compossible either.

A ratio perhaps may be ideal for some external contingent purposes (e.g. an ideal ratio of inhabitants to coconut trees to soil nutrients, all relata being finite and non-maximal and determined by e.g. contingent facts of dietary requirements of the inhabitants, nutritional value of the coconuts, ambient temperature, metabolic rate of the inhabitants and so on) but it cannot be maximally great or perfect in itself, by the very fact of its constitution by finite (delineated, constrained, limited) and thus not maximally great or perfect constituents - as Crimi accepts. Maximal greatness or perfection discussed by St Anselm, Plantinga and myself is therefore qualitatively different from greatness of a garden variety, not least because it suffers not measurement nor limitation.

Crimi identifies an objection to his proposal in the vicinity of the above discussion: "perhaps the notion of an ideal ratio of great-making island properties is itself inconceivable so that ideal islands exhibiting such a ratio are also inconceivable. Isn't it implausible that we could ever exactly specify an ideal ratio of great-making island properties, and so isn't it equally implausible that such an ideal ratio is conceivable?' The problem however is not our ability or otherwise to specify exactly an ideal ratio of great-making island properties but the very notions of proximity, ratios and great-making properties discussed above. 
Crimi further suggests that there is the possibility of two equally ideal islands which are equally great - but even if we grant them 'ideal' status by specifying some external contingent variable criterion for being 'ideal' that both of them meet neither of them would be maximally great or perfect, thus leaving St Anselm unscathed, and the notion of a maximally great or perfect island incoherent.

Unfortunately for Gaunilo and his supporters, proposing that there is an ideal ratio of great-making properties for an island saves his island from incoherence no better than proposing that there is one ideal size of an island - not only, as Plantinga put it, island qualities possess no intrinsic maximum, but they cannot accommodate imputed maximality by way of ratios or otherwise (Plantinga, 1974: 90-91). Both proposals fail because the idea of an island - indeed of anything that is finite, delineated and circumscribed as a matter of its own conception - cannot instantiate maximal greatness or perfection.

\section{Notes}

Milo Crimi, 'Ideally sized islands: Reply to Danielyan, Garrett and Plantinga', Analysis 77 (2), 273278.

Edgar Danielyan, ‘On behalf of St Anselm’, Analysis 75 (3), 405-407.

G. W. Leibniz, Sämtliche Schriften und Briefe, Series VI, Volume III, ed. by the Academy of Sciences of Berlin (Berlin: Academy of Sciences, 1923), p. 578.

Alvin Plantinga, God, Freedom, and Evil (Grand Rapids, MI: Eerdmans, 1974). 